Surface and Coatings Technology, Vol. 149, Issues 2-3, 15 January 2002, Pages 236-244

\title{
Smart Overlay Coatings - Concept and Practice
}

\section{J. R. Nicholls*, N. J. Simms*, W. Y. Chan ${ }^{+}$and H. E. Evans ${ }^{+}$ \\ * Cranfield University \\ + University of Birmingham}

Keywords: $\quad$ High Temperature : Graded Overlay Coatings : Corrosion Resistance Oxidation Resistance

\begin{abstract}
$\underline{\text { Abstract }}$
Smart overlay coatings are a functionally gradient coating system designed to provide high temperature corrosion protection over a wide range of operating conditions.
\end{abstract}

The "SMARTCOAT" design consists of an MCrAlY base, enriched first in chromium, then aluminium to provide a chemically graded structure. At elevated temperatures, above $900^{\circ} \mathrm{C}\left(1650^{\circ} \mathrm{F}\right)$, the coating oxidises to form a protective alumina scale. However, at lower temperatures this alumina scale does not reform rapidly enough to confer protection under type II hot corrosion conditions. The coating is therefore designed with an intermediate chromium rich interlayer, which permits the rapid formation of chromia healing areas of type II corrosion damage.

Laboratory and burner rig tests have been carried out on a series of developmental smart overlay coatings. These have shown that the development of an intermediate chromium rich phase provides protection under low temperature hot corrosion conditions, while the aluminium rich surface layer provides resistance to high temperature oxidation and type I hot corrosion. Thus the single application of "SMARTCOAT" permit operation over a broad range of industrial and marine turbine conditions. 


\section{$\underline{\text { Introduction }}$}

To improve fuel efficiency and performance one has seen a steady, continuous increase in the operating temperatures of the turbine sections of aero-, marine- and utility turbines over the past 20 years. This temperature rise has been met by the intelligent use of materials with increased temperature capability, through the use of advanced manufacturing technologies, including investment cast blades with improved cooling efficiencies and single crystal technology, and through the use of advanced coating systems [1-4].

Improvements in coating technology have paralleled these engine developments, with the aim of providing protection to these superalloy components from the increasing aggressive (higher temperatures, increased oxidation and corrosion rates, erosion) service environments. Thus, since the early 1960's one has seen the development of diffusion coatings, MCrAlY overlay coatings, modified diffusion coatings - for example platinum aluminides - and most recently thermal barrier coatings [4-8].

Smart overlay coatings are the latest developments in environmental protection coatings. They are chemically graded coatings, designed to provide an optimised corrosion response over a wide range of turbine operating conditions that are likely to be encountered in utility turbines, working with multi-fuel capability. The industrial driver is the design of high efficiency power plant, capable of operating on a wide range of fuels from natural gas, through kerosenes, diesel oils, residual oils and gaseous fuels made from coal, biomass and waste, using combined cycle power plant technologies. The requirement is for extended duty cycles - up to $30,000 \mathrm{~h}$ has been cited [9] - coupled with increased operating temperatures. Under such service conditions the engine may experience high temperature 
oxidation $\left(>950^{\circ} \mathrm{C}\right)$, type I hot corrosion $\left(800-950^{\circ} \mathrm{C}\right)$ and type II hot corrosion $\left(650-800^{\circ} \mathrm{C}\right)$ across a single component.

Smart coat technology has been designed to provide optimised protection to this mixed range of environments loads.

\section{Environmental Protection Coatings}

High temperature environmental protection coatings are designed from the understanding of oxidation and hot corrosion processes that has been developed over the last half century [1014].

Hot corrosion problems (type I and type II hot corrosion, vanadic corrosion) are a direct result of salt contaminants such as $\mathrm{Na}_{2} \mathrm{SO}_{4}, \mathrm{NaCl}$ and $\mathrm{V}_{2} \mathrm{O}_{5}$ which in combination produce low melting point deposits which dissolve the protective surface oxides. A number of fluxing mechanisms has been proposed to account for the different corrosion morphologies that are observed [12-14] and this has resulted in the general classification of high temperature (type I, $800-950^{\circ} \mathrm{C}$ ), hot corrosion low temperature (type II, $600-800^{\circ} \mathrm{C}$ ) hot corrosion and vanadic corrosion $\left(535-950^{\circ} \mathrm{C}\right)$. These corrosion processes can be separated into an initiation and propagation stage. During the initiation stage the corrosion rate is comparatively low as breakdown of the surface oxide occurs. However, once this has happened and repair of the oxide is no longer possible, then the propagation phase results in the rapid consumption of the alloy. Since the coating provides for the repair of the protective surface oxide scales, the initiation stage can be extended, ideally for the design life of the component. However, once coating penetration occurs, the propagation stage often results in catastrophic corrosion rates. 
Thus fundamental understanding provides the science behind the SMARTCOAT concept: the coating is designed to maintain a stable protective oxide, but if this oxide is breached it will repair itself effectively to re-establish protection.

As a background to the development of SMARTCOAT technology, the corrosion performance of a wide range of diffusion and overlay coatings, under high temperature oxidation and type I and type II hot corrosion conditions have been extensively reviewed [8, 15, 16]. The platinum modified aluminides performed exceptionally well under high temperature oxidation conditions and in type I hot corrosion environments $\left(800-950^{\circ} \mathrm{C}\right)$ $[17,18]$ but performed less well under type II hot corrosion conditions, although out performing conventional aluminides $[15,16]$. Of the other diffusion coatings, the silicon containing diffusion aluminides (for example Sermetel 1515) perform well under type II hot corrosion conditions. Chromised and chrome-aluminised coatings also offer protection under type II corrosion conditions. Thus silicon containing and/or chromium-rich diffusion coatings offer improved corrosion resistance at the lower temperatures that are often encountered within utility turbine environments $[16,17,19-21]$.

Overlay coatings of classic design, with $18-22 \% \mathrm{Cr}$ and $8-12 \% \mathrm{Al}$, generally perform better at higher temperatures where oxidation is the dominant failure mode (above $900^{\circ} \mathrm{C}$ ) reflecting the good adherence of the thin alumina scales which is promoted by the presence of active elements such as Yttrium. Generally under these high temperature oxidising conditions NiCrAlY's and NiCoCrAlY's out perform the cobalt based systems.

However, at low temperatures where type II hot corrosion predominates, $650-800^{\circ} \mathrm{C}$, corrosion rates for the NiCrAlY and NiCoCrAlY overlay coatings can be relatively high. 
CoCrAlY's generally out perform NiCrAlY based systems, with the high chromium containing CoCrAlY's showing best performance [8, 16, 19-22]

This is illustrated schematically in Figure 1 reproduced from a paper by Novak (1994) [22] and is similar to an early diagram by Mom in 1981 [21].

Methods have been investigated to improve the traditional MCrAlY coatings by use of a platinum underlayer and overlayers [23]. Other additions such as Ti, Zr, Hf, Si and Ta have been examined $[24,25,26]$. Surface modification by CVD, PVD or slurry cementation techniques $[27,28]$ have also been considered with varying degrees of success.

Surface modification results in the formation of a duplex coating structure and this can result in improved performance, for example, a pulse aluminised CoNiCrAlY coating exhibits superior corrosion resistance at 750 and $850^{\circ} \mathrm{C}$ compared to its plasma sprayed counterpart [15]. Similarly the GT29, patented overlay coating [29] is formed by a gas phase diffusion treatment of a plasma sprayed MCrAlY coating. Silicon modifications to the surface of CoCrAlY coatings [30] have also been proposed and improve the resistance to low temperature hot corrosion.

The smart overlay coating concept, introduced within this paper, looks to extend these surface modification concepts by grading not only the aluminium profile, but also the chromium, to further improve oxidation/corrosion resistance. 


\section{The "Smart Coating" Concept}

In order that a single coating can operate successfully over a range of temperatures with different forms of corrosion attack - high temperature oxidation, type I and type II hot corrosion - it needs to respond to local temperature in such a way that it will form either an alumina or chromia protective layer as appropriate. High purity alumina scales offer the best protection under high temperature oxidation conditions, and this has been a major drive behind the development of platinum aluminide coating technology. Chromia scales form more readily at low to intermediate temperatures, are more resistant to salt fluxing and thus provide a rapid repair route under hot corrosion conditions.

In a "Smart overlay coating" these joint requirements are achieved through the use of a chemically-graded coating structure enriched in aluminium and chromium as illustrated in Figure 2. Here the basic coating is a standard MCrAlY (in this study either Co32Ni21Cr8A10.5Y or Ni25Cr6Al0.4Y) that has been enriched at its outer surface in aluminium, sufficient to form $\beta-\mathrm{NiAl}$. Before this aluminising treatment, the MCrAlY is pretreated to form an intermediate layer rich in chromium (this pretreatment process is proprietary and determines the structure and performance of the smart coating) [31,32].

Under high temperature oxidation, and type I hot corrosion conditions, above $800^{\circ} \mathrm{C}$, the outer layer of the coating reacts to form an alumina oxide layer, providing appropriate protection under these oxidation/corrosion conditions. The chromium rich intermediate layer behaves as a diffusion barrier limiting the loss of aluminium by diffusion into the MCrAlY coating. It is also believed to limit the movement of base metal elemental additions out to the $\beta-\mathrm{NiAl}$ rich region. 
At lower temperatures, $600-800^{\circ} \mathrm{C}-$ in the type II corrosion regime - this outer layer of the coating offers less protection. It is sacrificial and the rate of type II pitting corrosion is then limited by the chromium rich interlayer which forms a more rapidly growing chromia protective scale at these temperatures.

Thus the "Smart" coating functions by providing a more optimum response to corrosion attack that may be observed in industrial gas turbines at different aerofoil surface temperatures. It should be appreciated that this optimised response results from the formation of the most suitable protective oxide scale in each temperature range of operation envisaged. In this sense, the coating responds to its environment in a pseudo-intelligent manner and has been given the generic name of SMARTCOAT.

\section{Optimisation of Corrosion Resistant Compositions}

A critical step in the design of SMARTCOAT was understanding the role MCrAl-based alloy composition played in the determination of the corrosion resistance of the overlay coatings. Particularly the role of high chromium, high aluminium containing coating in combating type II hot corrosion.

Early work on overlay coatings [33] considered a range of cobalt based materials with additions of chromium between $20-40 \mathrm{wt} \%$, aluminium between $12-20 \mathrm{wt} \%$ and yttrium at the $0.5 \mathrm{wt} \%$ level. From this study, the most successful coating following burner rig trials $\left(1093^{\circ} \mathrm{C}\right.$ for $\left.1100 \mathrm{~h}\right)$, tensile and stress rupture tests was $\mathrm{Co} 25 \mathrm{Cr} 14 \mathrm{~A} 10.5 \mathrm{Y}$ and this formed the basis from which the majority of the MCrAlY oxidation/corrosion resistant coatings have been developed. Since this pioneering study, much research has been undertaken into the MCrAlY series of alloys. New compositions have been identified for marine service 
$[20,34,35]$, for utility turbine conditions $[36,37]$ and for high temperature cyclic oxidation [38,39]. Thus, since 1970, the base alloy composition has changed to include NiCrAlY's, CoNiCrAlY's and NiCoCrAlY's and various oxygen active elements have been added, including $\mathrm{Hf}, \mathrm{Zr}$, Si and Ta. However, the base compositions of most of these overlay coatings still contain 5-14wt $\% \mathrm{Al}$ and $18-30 \mathrm{wt} \% \mathrm{Cr}$; compositions originally optimised for a high temperature oxidation protection, as evident from Talboom et al's original test condition $1093^{\circ} \mathrm{C}$ for $1100 \mathrm{~h}$.

Under type II hot corrosion conditions, work by Luthra and co-workers [20,40] showed the benefit of high chromium containing alloys, with chromium contents up to $40 \mathrm{wt} \%$, while studies at Cranfield have demonstrated the benefits of high chromium and high aluminium levels, with an alloy containing $33 \mathrm{wt} \% \mathrm{Cr}$ and $33 \mathrm{wt} \% \mathrm{Al}$ exhibiting optimum corrosion performance at $750^{\circ} \mathrm{C}$ [41-43]. Figure 3 illustrates a ternary diagram at $750^{\circ} \mathrm{C}$, overlayed with iso-corrosion contours [43] which demonstrates that the most corrosion resistant alloys at this temperature contain chromium levels between $24-40 \mathrm{wt} \%$ and aluminium levels between 27-37wt\%, much higher than the levels in conventional MCrAlY coatings. It should be further noted from Figure 3 that optimum corrosion performance under type II hot corrosion is associated with a $\mathrm{Cr} / \mathrm{Al}$ ratio close to 1.0 (for a wide range of base alloy contents. The optimum composition is $\mathrm{Ni} 33 \% \mathrm{Cr} 33 \% \mathrm{Al}$ in wt. $\%$.

Studies of these optimised corrosion resistant alloys was possible through the use of vapour phase alloy design [41,42]. This multi-target sputtering approach allows many alloy compositions to be deposited in a single deposition run and thus corrosion contour maps can be generated easily once the laboratory simulation environment has been selected. The methodology is detailed in reference 42. Using this approach, ternary maps with iso- 
corrosion contours were produced at $650,700,750,800$ and $950{ }^{\circ} \mathrm{C}$. These studies confirm the premise that high chromium containing alloys offer superior type II corrosion resistance, and further demonstrate that as the temperature is increased the overlay coating should contain increased levels of aluminium, and reduced chromium contents, with the compositions originally proposed by Talboom et. al. near optimum under high temperature oxidation, when based on an MCrAl-X alloy design.

Thus from the iso-corrosion maps, the best corrosion performance at each of the test temperatures was obtained with alloy compositions in the following ranges:-

$650^{\circ} \mathrm{C}$ : $\quad$ alloys rich in chromium, with $\mathrm{Cr}>40 \mathrm{wt} \%$ and $\mathrm{Al}$ levels between $5-10 \mathrm{wt} \%$. $700^{\circ} \mathrm{C}$ : alloys rich in chromium, with $\mathrm{Cr}>40 \mathrm{wt} \%$, but containing 20-40wt\% aluminium.

750 and $800^{\circ} \mathrm{C}$ : alloys contain $24-40 \mathrm{wt} \% \mathrm{Cr}$ and $27-37 \mathrm{wt} \% \mathrm{Al}$ : the optimum being $33 \mathrm{wt} \% \mathrm{Cr}, 33 \mathrm{wt} \% \mathrm{Al}$

$950^{\circ} \mathrm{C}: \quad$ alloys with $16-24 \mathrm{wt} \% \mathrm{Cr}$ and $13-18 \mathrm{wt} \% \mathrm{Al}$

$1093^{\circ} \mathrm{C}^{+}: \quad$ alloys centred on $25 \mathrm{wt} \% \mathrm{Cr}$ and $14 \mathrm{wt} \% \mathrm{Al}$

Conventional commercial MCrAlY coatings have compositions containing: $18-30 \mathrm{wt} \% \mathrm{Cr}$, plus 5-14wt\% Al and so are a compromise between optimal protection for Type I corrosion and high temperature oxidation.

+ Footnote data from Talboom et al (reference 33) 


\section{Coating Manufacture}

These chemically graded coating structures were produced in this study through a combination of spraying technologies and chemical vapour deposition. However, any method of depositing an MCrAlY coating can be used, including PVD technologies, electroplating as well as plasma spray and flame spray technologies. The added benefit is not soley in the base alloy composition, but in how it is treated to produce the graded microstructure.

Both argon shrouded, plasma spraying and high velocity oxy-fuel spraying (HVOF) have been used successfully to deposit the MCrAlY base. CoNiCrAlY (Amdry 995) and a NiCrAlY (Amdry 963) have been used as base coating systems.

The second step is to surface treat the as-sprayed MCrAlY to form the chromium rich interlayer. This step is proprietary, but is designed to produce a continuous inner zone containing some $60 \mathrm{wt} \% \mathrm{Cr}$.

The final step is an aluminising treatment, to develop the outer $\beta$-NiAl oxidation resistant layer. Thus without the proprietary intermediate layer treatment the production route is similar to the General Electric proprietary coating GT29+. Both high activity and low activity aluminising process have been used to produce SMART coatings, using both pack cementation and gas phase CVD processes. These process differences are reflected in the SMARTCOAT series, with coatings coded SmC105 through SmC155 (see later corrosion studies). 
The combination of spray deposition (HVOF or plasma spraying), the surface pretreatment, then diffusion aluminising results in a layered microstructure, an example of which is illustrated in Figure 4. This coating (SmC155) clearly shows the three zones developed within a SMARTCOAT: the outer aluminide diffusion zone (A), the chromium rich, displaced intermediate zone (B) and the remaining HVOF/plasma spray coating (C) - a plasma sprayed coating for the example presented in Figure 4. The analyses at points A-C are summarised in Table 1.

It is the chromium rich interlayer (B) that distinguishes SMARTCOAT structures, from the more traditional graded structures produced by over-aluminising a MCrAlY overlay coating, for example GT29+. This interlayer is optimum for type II corrosion resistance when its composition lies in the range 38-60 wt\%Cr, 20-36wt\% Al balance nickel. One general observation is that NiCrAlY based systems perform better than those based on CoNiCrAlY alloys, as there is a lower risk of sigma phase formation with the NiCrAlY based graded coating microstructure.

\section{Hot Corrosion Resistance of SMARTCOAT Structures}

The hot corrosion performance of SMARTCOAT variants were evaluated using a salt recoat test procedure [44], in controlled gaseous environments with daily replenishment of corrosion deposits. Both the NiCrAlY and CoNiCrAlY based coatings were evaluated. For each family of coatings hot corrosion tests were performed at 700 and $800^{\circ} \mathrm{C}$. The test duration was $500 \mathrm{~h}$ in an air-400 vpm $\mathrm{SO}_{2} / \mathrm{SO}_{3}$ gaseous environment. The salt used was a eutectic mixture, $80 \% \mathrm{Na}_{2} \mathrm{SO}_{4} / 20 \% \mathrm{~K}_{2} \mathrm{SO}_{4}$, replenished every $20 \mathrm{~h}$ at a rate of $0.3 \mathrm{mg} / \mathrm{cm}^{2}$ (an average deposition flux of $0.015 \mathrm{mg} / \mathrm{cm}^{2} / \mathrm{h}$ ). Six variants of the SMARTCOAT were 
evaluated in each test together with two standard, industrial gas turbine coatings - a platinum aluminide (RT22) and a triple layered silicon aluminide (Sermetel 1515).

Corrosion loss was evaluated using dimensional metrology as discussed in reference 44, with the metal loss analysed statistically (see reference 45) to estimate the maximum corrosion rates.

The commercial coatings exhibited class type II hot corrosion at $700^{\circ} \mathrm{C}$ and type I hot corrosion at $800^{\circ} \mathrm{C}$, as can be seen in Figure 5. After $500 \mathrm{~h}$ exposure at $700^{\circ} \mathrm{C}$, the RT22 coating was penetrated through to the interdiffusion zone, while at $800^{\circ} \mathrm{C}$ it had been completely consumed and the substrate (IN738LC) was also severely attacked.

By comparison, all SMARTCOAT variants show little attack as can be seen for variant $\mathrm{SmC155H}$ in Figure 5. SmC155H was one of the worst attacked of these SMARTCOAT variants, particularly at $800^{\circ} \mathrm{C}$. Table II summarises the measured corrosion rates for a number of smart coatings compared to the industrial standards RT22 (a platinum aluminide) and Sermetel 1515 (a triple layered silicon aluminide treatment). The smart coating matches the performance of the best type I hot corrosion resistant (RT22) and type II hot corrosion resistant (Sermetel 1515) diffusion coatings. Thus a single coating treatment provides both type I and type II hot corrosion protection.

A further point to note is that the SMARTCOAT structure also modifies the mode of attack at both 700 and $800^{\circ} \mathrm{C}$. No longer are deep pits observed - see Figure 5 - instead the corrosion attack only penetrates the outer diffusion aluminide treated zone, stopping at the chromium rich corrosion barrier. Once this barrier zone is reached the outer aluminide 
layer is progressively consumed, providing cathodic protection in these molten salt deposits that form under hot corrosion conditions.

This benefit cannot be attributed solely to the over aluminising treatment, as the overaluminised MCrAlY coatings were also severely attacked in this aggressive laboratory test. It is the combination of over aluminising and the chromium rich, corrosion barrier layer (characteristic of SMARTCOAT) that provides this additional protection. The best of the smart coating variants lost between $25-30 \mu \mathrm{m}$ at maximum, at $700^{\circ} \mathrm{C}-\mathrm{SmC} 155-$, and at maximum $15-35 \mu \mathrm{m}$ at $800^{\circ} \mathrm{C}-\mathrm{SmC} 153$

\section{Future Developments in Smart Coating Technology}

As with all high temperature, environmental protection systems selective oxidation necessarily depletes the coating of beneficial scale forming elements $(\mathrm{Al}, \mathrm{Cr}$ or $\mathrm{Si})$ as the protective oxide is formed and grows. Hot corrosion reactions exacerbate this problem, such that ultimately the coating loses the ability to reform the protective oxide if damaged as a result of corrosion, or oxide spallation during shut down or cyclic operation. As a consequence the economic benefits associated with long term, or high temperature, operation are at risk. The way forward is to improve the coatings repair capability by incorporating both reservoir phases and scavenger phases within the smart coating system. Both will provide a self healing capability and thus extend coating life.

A reservoir phase is an intermetallic compound that can source scale forming elements as the levels of these elements are depleted in the coating. Possible systems under investigation include $\mathrm{Al}_{2} \mathrm{Y}$ and $\mathrm{NiAl}_{3}$. The former can source both aluminium and yttrium, confering extended protection under high temperature oxidation conditions. The latter 
sources aluminium, but more importantly remains molten for an extended time during thermal spraying processes and therefore permits closure of open inter-particle boundaries [46], a source of rapid coating degradation due to increased oxidation within the near surface region of the coating. A companion paper discusses the enhanced degradation due to the formation of isolated small diffusion cells [47].

Figure 6 illustrates the incorporation of $\mathrm{Al}_{2} \mathrm{Y}$ as a reservoir phase within the microstructure of a HIP processed SMARTCOAT structure. The optimum position of the reservoir phase depends on diffusion rates to provide a sufficient flux to ensure that the near surface elemental composition ( $\mathrm{Al}$ and $\mathrm{Y}$ in this example) is sufficient to repair and maintain the protective oxide.

A scavenger phase works differently. Now the phase is added to react, and entrap, tramp elements that may move from the alloy substrate through the coating to the metal oxide interface, so compromising the stability of the protective oxide scale. The presence of minute quantities of sulphur have long been recognised as detrimental [48-50] compromising the adhesion of the protective, thermally grown oxide. Other elements may work in a similar manner including phosphorus and possibly carbon.

Similarly, diffusion of deliberate alloy additions from the substrate into the coating may also be detrimental to coating performance. Molybdenum and tungsten have long been recognised for their influence on the acidic fluxing of oxide scales under hot corrosion conditions, while too high a level of titanium, in the near surface region, leads to the formation, of rutile within or under the alumina scales compromising alumina scale adhesion. 
To overcome such problems, scavenger phases can be added to the coating. Figure 7 illustrates the incorporation of $\mathrm{Cr}_{3} \mathrm{C}_{2}$ into a graded overlay coating structure. The $\mathrm{Cr}_{3} \mathrm{C}_{2}$ particles are present as a network of carbides around prior splat boundaries and are positioned within the coating, just above the coating substrate interface. A scavenger phase must have transitional stability, that is within the as-deposited coating it is stable but if surrounded by sufficient elements that can form more stable compounds it will breakdown, sourcing a scavenger element. For the above example $\mathrm{Cr}_{3} \mathrm{C}_{2}$ acts as a source of carbon to tie up outward diffusing titanium. Equally in the foregoing discussion, $\mathrm{Al}_{2} \mathrm{Y}$ was considered as a reservoir phase but it could equally scavenge sulphur through interacting with the yttrium. Chromium carbide is another scavenger phase, relative to titanium, molybdenum and tungsten, it is partially stable reacting to form TiC, for example, and releasing chromium. Chromium carbide has been demonstrated by the authors to be a very effective scavenger phase for tramp element, titanium diffusion [51], limiting the transport of titanium through to the metal oxide interface and therefore prolonging the life of a smart coating system. Figure 8 illustrates this behaviour. Note, the high titanium peaks near the smart coating/substrate interface trapping titanium as carbides as moves outward from the substrate due to diffusion.

\section{Conclusions}

1) A new type of chemically graded coating has been designed, from a knowledge of the corrosion mechanisms operating under high temperature oxidation, type I and type II hot corrosion.

2) The coating is graded in aluminium and chromium content, with an outer $\beta$-NiAl aluminium rich composition to confer high temperature oxidation resistance and 
type I hot corrosion protection and an interlayer, rich in chromium, to confer type II corrosion protection.

3) The coating confers protection over an extended range of service temperatures and corrosion environments likely to be experienced in an industrial gas turbine. It does this in a pseudo-intelligent manner by responding to the temperature and environment, to form the optimum protective oxide scale: alumina at high temperatures and chromia under type II corrosion conditions.

4) Results of laboratory corrosion tests are extremely promising, with the best of the SMARTCOAT variants, matching or outperforming RT22, a platinum aluminide coating, and Sermetel 1515, a multilayered silicon-aluminide, at 700 and $800^{\circ} \mathrm{C}$. Unlike both of these commercially available coatings, SMART coatings can be deposited substantially thicker and so would offer a significant improvement in coating service life.

5) The concepts of reservoir and scavenger phases, as part of a smart coating system have been demonstrated. The selective inclusion of such phases within a high temperature coating system can further extend coating life by limiting oxide scale failure, either through sourcing beneficial elemental additions (reservoir behaviour) or trapping detrimental elements (scavenger behaviour). 


\section{Acknowledgements}

The authors wish to thank all colleagues involved in the smart overlay coating project for their input, particularly the close collaboration with various industrial partners during the development of the SMARTCOAT concept. These include Alstom Power Plc, Diffusion Alloys Ltd, Poetons Ltd, C. A. Technology and British Coal Plc. The financial support of the EPSRC and the D.T.I. LINK Surface Engineering Initiative is gratefully acknowledged.

\section{$\underline{\text { References }}$}

1. D. Driver, D. H. Hall, and G. W. Meetham in "The Development of the Gas Turbine Engine”, Applied Science Publishers, London (1981).

2. J. C. Williams, "The Development of Advanced Gas Turbines" in "Materials for Advanced Power Engineering II, p1831-1846, Kluwer Acad. Pub. Dordrecht/Boston. London (1994).

3. R. J. Hill, "The Future of Gas Turbine Engines" in 'Propulsion and Energy Issues for the $21^{\text {st }}$ Century' AGARD CP824, Chapter 2, March 1997.

4. 'Coatings for High Temperature Structural Materials' NMAB report of the NRC, Washington DC, National Academic Press (1996).

5. G. W. Goward, in High Temperature Corrosion (ed. R. A. Rapp), p553, NACE, Houston, TX (1983).

6. J. W. Fairbanks and R. J. Hecht, Mater. Sci. Engng 88, 321 (1987).

7. $\quad$ S. R. J. Saunders and J. R. Nicholls, Mater. Sci. Techno. 5780 (1989).

8. J. R. Nicholls "Design of Oxidation Resistant Coatings" JoM, 28-35 (2000).

9. Alstom Power, Technical Newsletter, Issue 8, MEC, Whetstone, Leics. (1998).

10. O. Kubaschewski and B. E. Hopkins, "Oxidation of Metals and Alloys", Butterworths, London (1967).

11. P. Kofstad, 'High Temperature Oxidation of Metals, Wiley, New York, (1966).

12. N. Birks and G. H. Meier. 'Introduction to High Temperature Oxidation of Metals' Edward Arnold Publishers, London (1983).

13. P. Kofstad, 'High Temperature Corrosion', Elsevier, (1988).

14. C. S. Giggins and F. S Pettit, 'Hot Corrosion Degradation of Metals and Alloys - A Unified Theory-PWA-Report FR-11545 (1979).

15. J. R. Nicholls, D. J. Stephenson, P. Hancock, M. I. Wood and J. E. Restall, In Proc. Workshop on 'Gas Turbine Materials in a Marine Environment', Bath UK Ministry of Defence, Session 2, Paper 7, published by U.K. Sea Systems Controllerate, Bath., UK, (Nov.1984).

16. J. R. Nicholls and S. R. J. Saunders, in High Temperature Materials for Power Engineering' (Eds. E. Bachelet et al), Kluwer Academic Publishers, Dordrecht, (1990), p865-875. 
17. G. W. Goward and L. W. Cannon, "Pack Cementation Coatings for Superalloys, History, Theory and Practice", ASME Paper 87-GT-50, New York, American Society Mechanical Engineers, 1988.

18. G. W. Goward and D. H. Boone, Oxid. Met., $\underline{3}$ (1971), 475.

19. M. Malik, Morbioli and P. Huber. In 'High Temperature Alloys for Gas Turbines' Conf Proc. (ed. R. Brunetaud et. al.) 87-98, Dordrecht, D. Reidel Publishing Co (1982).

20. K. L. Luthra and O. H. LeBlanc, Mater, Sci. \& Eng. 88 (1987), 329.

21. A. J. A. Mom, NLR Report MP 81003U, Amsterdam. 1981.

22. R. C. Novak, (1994), cited in reference 17.

23. J. T. Prater, J. W. Patten, D. D. Hayes and R. W. Moss, im Proc. $2^{\text {nd }}$ Conf. on 'Advanced materials for alternate fuels capable heat engines', (eds J. W. Firbanks and J. Stringer), Report No. 2639SR, 7/29-7/43; Palo Alto, CA EPRI (1981).

24. C. Duret, A. Davin, G. Marrijnissen and R. Pichoir, in "High Temperature Alloys for Gas Turbines", (Conf Proc.) (Eds. R. Brunetaud et al.) p53-87; Dordrecht, D. Reidel Publishing Co. (1982).

25. S. R. J. Saunders and J. R. Nicholls, Thin Solid Films, 119, (1984) 247.

26. N. S. Bornstein and J. Smeggil, in 'Corrosion of Metals Processed by Directed Energy Beams', Met. Soc. AIME, p147-158 (1982).

27. J. E. Restall and C. Hayman, in 'Coatings for heat engines' (Workshop Proc.,) (ed. R. L. Clarke et al.) 347-357; Washington, DC, US Department of Energy (1984).

28. J. A. Goebel, R. J. Hecht and J. R. Vargas, in Proc. $4^{\text {th }}$ Conf on 'Gas turbine materials in a marine environment', Annapolis, MD, published by Naval Sea Systems Command, Washington DC, pp635-653, (June 1979).

29. J. R. Rairden. III. U.S. Patent 3,874,901 (1975).

30. A. R. Nicoll, in 'Coatings and surface treatment for corrosion and wear resistance', (eds. K. N. Strafford et al) p180; Chichester, Ellis Horwood (1984).

31. J. R. Nicholls 'Smart Coatings' - A Bright Future, Materials World 4 (1), 19-21 (1996).

32. J. R. Nicholls, N. J. Simms, S. Neseyif, H. E. Evans, C. Ponton. and M. Taylor, 'Hot Corrosion of Smart Overlay Coatings", in "High Temperature Corrosion and Materials Chemistry (ed. M. McNallan, E. Opila, T. Maruyama and T. Narita) Electrochem. Soc. Proceedings, Vol. 99-38, 270-281 (2000).

33. F. T. Talboom, R. C. Elam and L. W. Wilson, Evaluation of advanced superalloy production systems, NASA Report CR7813, PWA 4055 (A70), NASA, Houston TX (1970).

34. $\quad 3^{\text {rd }}$ US/UK Conf. on Gas Turbine Materials in a Marine Environment, UK MoD Ship Department, Bath UK (1976).

35. $\quad 4^{\text {th }}$ US/UK Conf. on Gas Turbine Materials in a Marine Environment, US Naval Sea Systems Command and UK MoD Shop Department, Annapolis, MD (1979).

36. J. W. Fairbanks and J. Stringer (eds), Proc. First Conf. on Advanced Materials for Alternative Fuel Capable Directly Fired Heat Engines. CONF-790749, US DoE and EPRI, Castine, MA (1979).

37. J. W. Fairbanks and J. Stringer (eds), Proc. Second Conf. on Advanced Materials for Alternative Fuel Capable Heat Engines, EPRI Report RD-2369-SR (1982).

38. J. L. Smialek, C. A. Barrett and J. C. Schaeffer, AMS Handbook Vol. 20, Materials Selection and Design, pp589-602, ASM International, Materials Park, OH, 1997.

39. C. A. Barrett and C. E. Lowell, Oxid. Met. 11 (4), 199 (1977).

40. K. L. Luthra and D. A. Shores, J. Electrochem. Soc. 127, 2202 (1980). 
41. J. R. Nicholls, K. J. Lawson, G. Chester, L. H. al Yasiri and P. Hancock, Elsevier Applied Science (1988) p295-307.

42. J.R. Nicholls, P. Hancock and L. H. al Yasiri, Materials Science and Technology, 5, p799-805 (1989).

43. J. R. Nicholls, K. J. Lawson, L. H. al Yasiri and P. Hancock, Corrosion Science Vol. 35, No5-8, pp1209-1223, (1993).

44. N. J. Simms, J. E. Oakey and J. R. Nicholls, J. Electrochem. Soc. Proceedings, Vol. 99-38, p305-316 (2000).

45. J. R. Nicholls and P. Hancock, "The Analysis of Oxidation and Hot Corrosion Data A Statistical Approach, NACE-6, p198 (1983).

46. W. Y. Chan, H. E. Evans, C. B. Ponton, J. R. Nicholls and N. J. Simms, Materials at High Temperatures 17 (2) 173-178 (2000).

47. H. E. Evans and M. P. Taylor, Oxid. Met. 55, 17-34, (2001).

48. J. G. Smeggil, A. W. Funkenbusch and N. S. Bornstein, Met. Trans 17a 923-938 (1986).

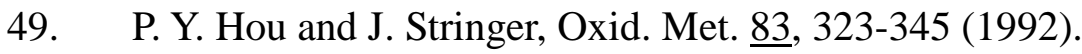

50. J. L. Smialek, Met. Trans. A $22 \mathrm{~A}, 739-752$ (1991).

51. W. Y. Chan, H. E. Evans, K. A. Simpson, N. J. Simms and J. R. Nicholls, unpublished work (2001). 


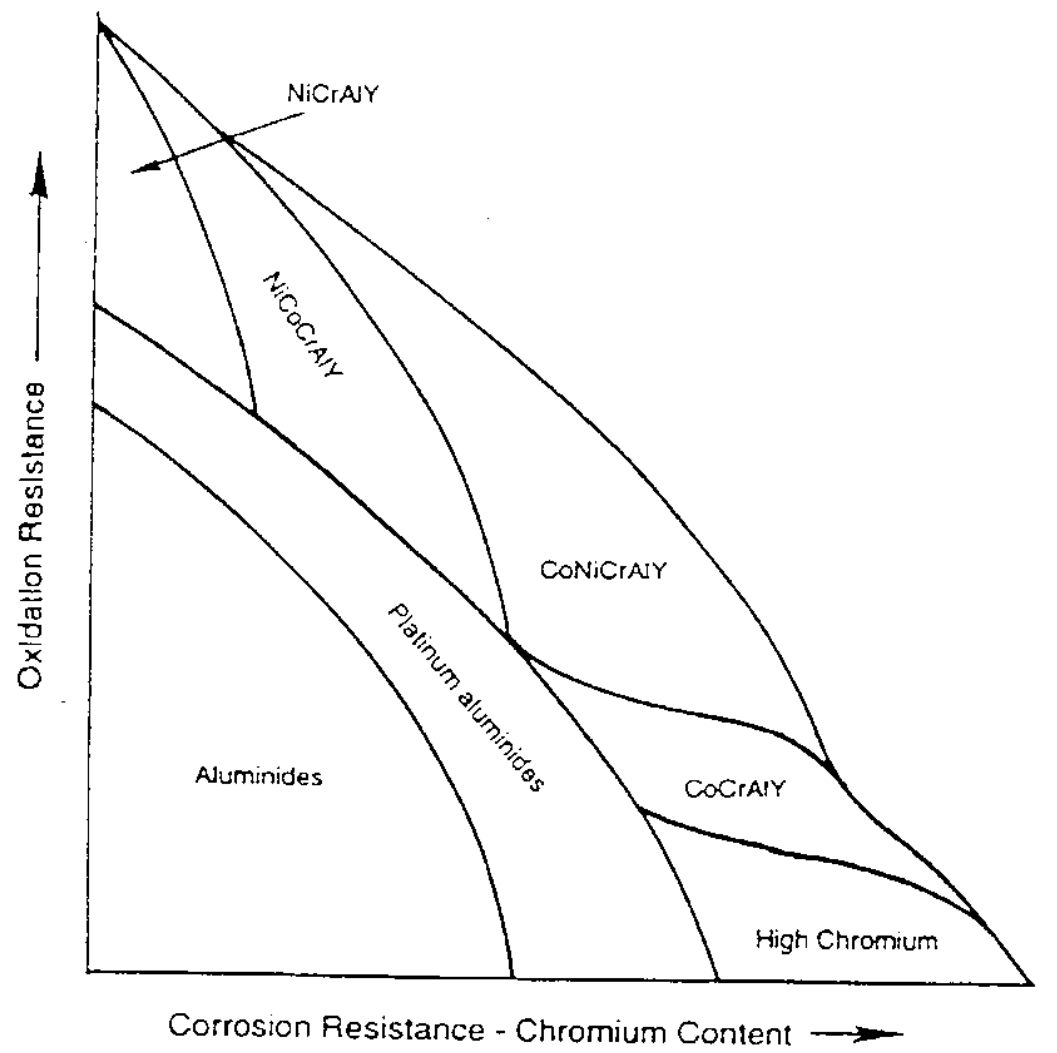

Figure 1 Relative oxidation and corrosion resistance of high temperature coating Systems [21,22]

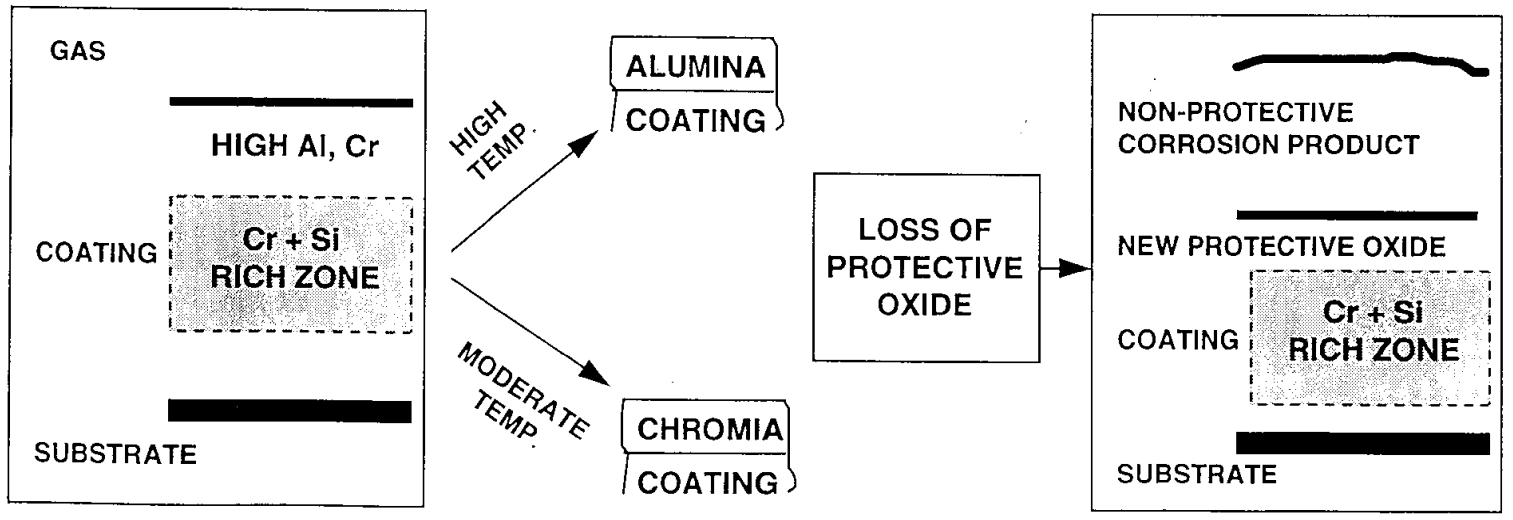

Figure 2 Smart overlay coating concepts [31,21] 


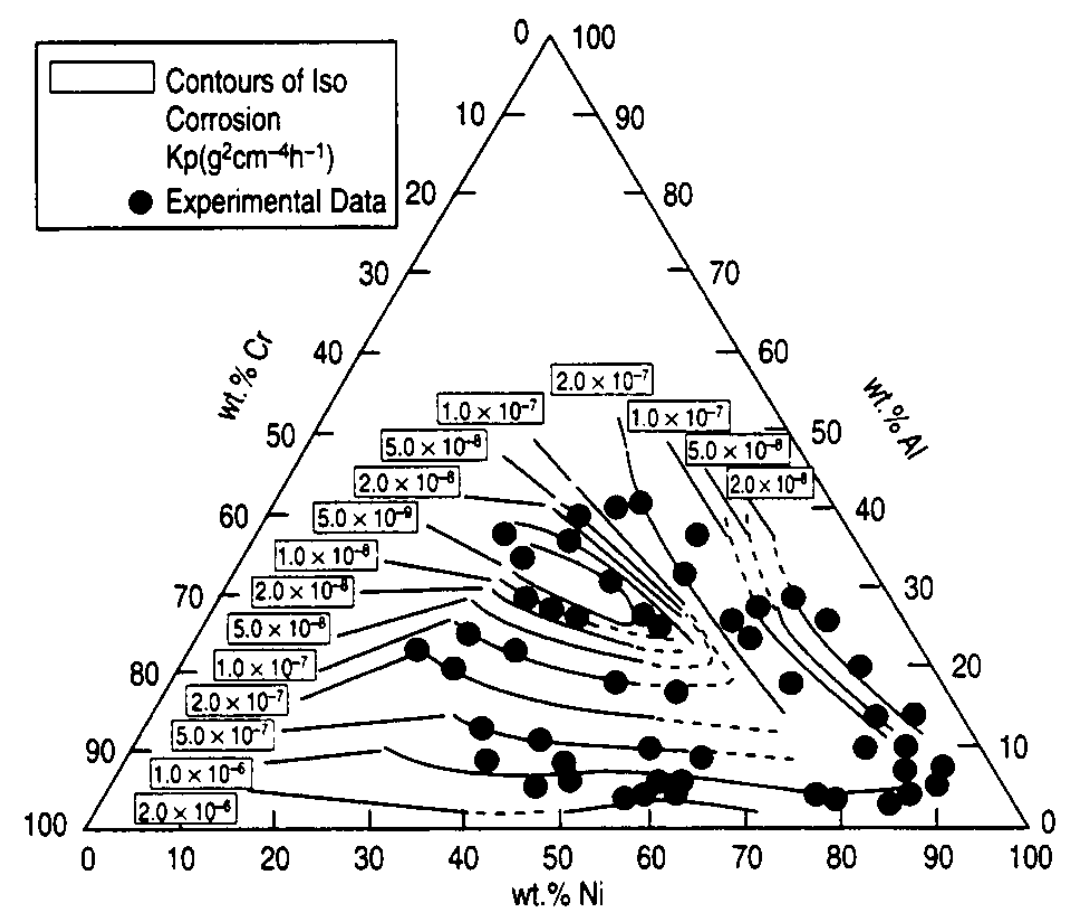

Figure 3 Iso-corrosion map at $750^{\circ} \mathrm{C}$ for $\mathrm{NiCrAl}$-based coatings under type II hot corrosion conditions

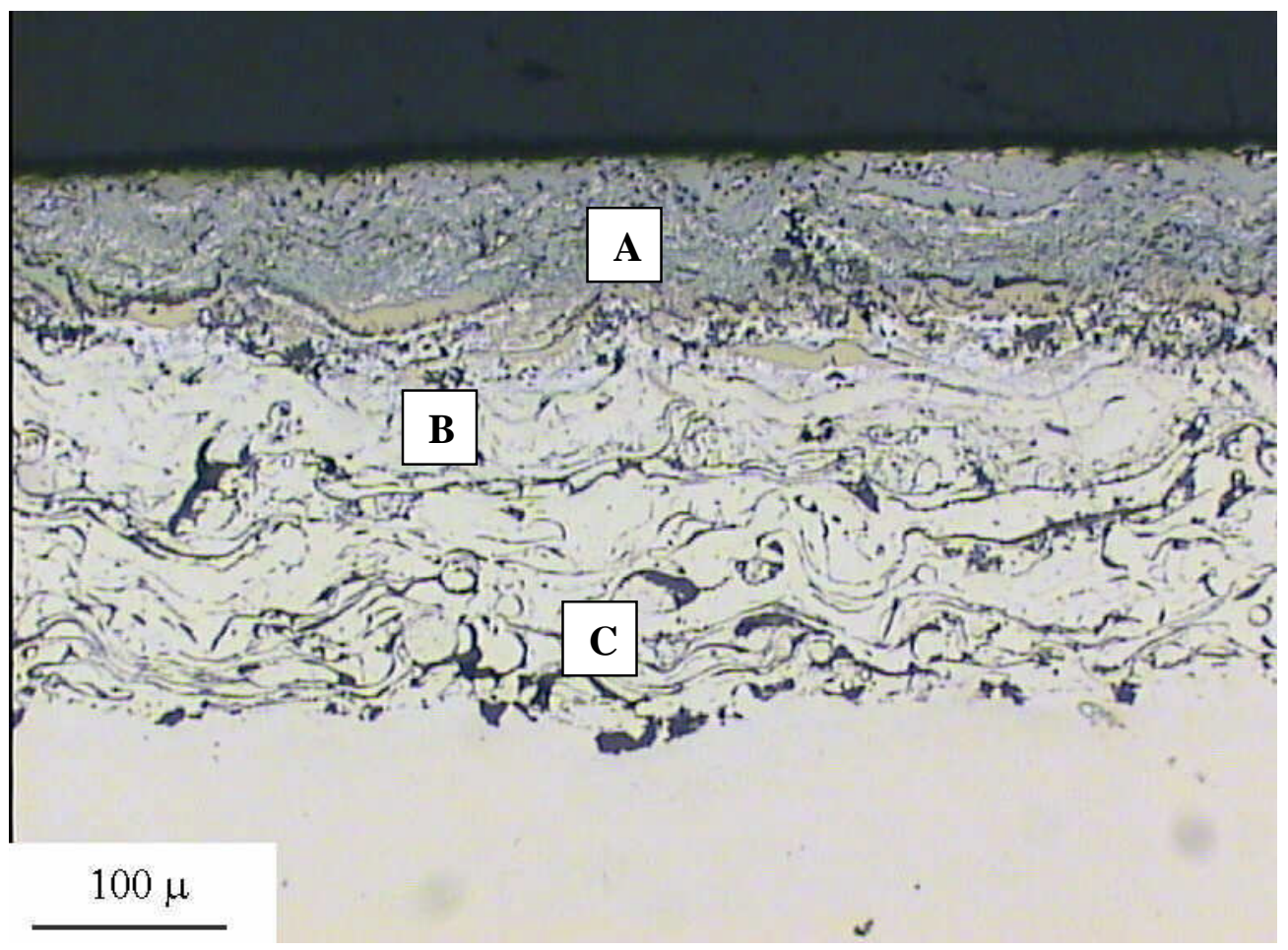

Figure 4 A micrograph of Smartcoat SmC155H showing the three layered Microstructure that is characteristic of Smartcoat. 
Figure 5 


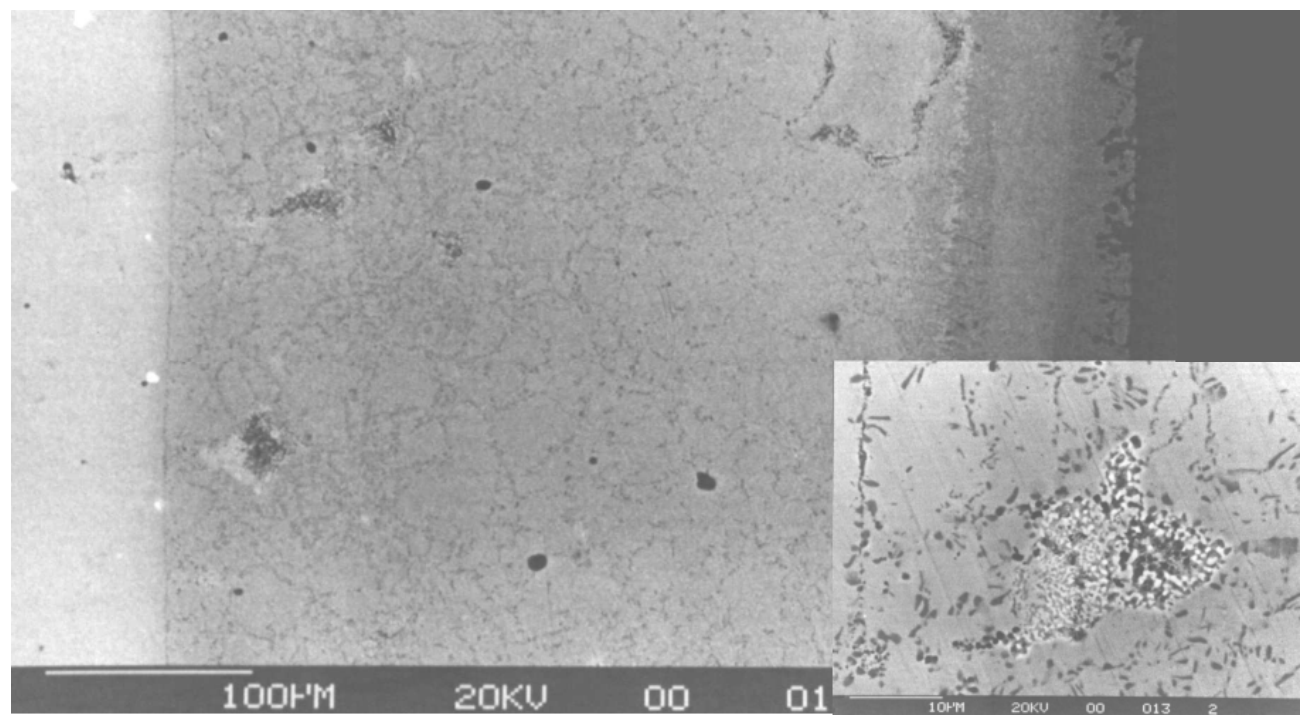

Figure 6 Back scattered electron image of $\mathrm{Al}_{2} \mathrm{Y}$ dispersed phase in a HIPped Smart coating.

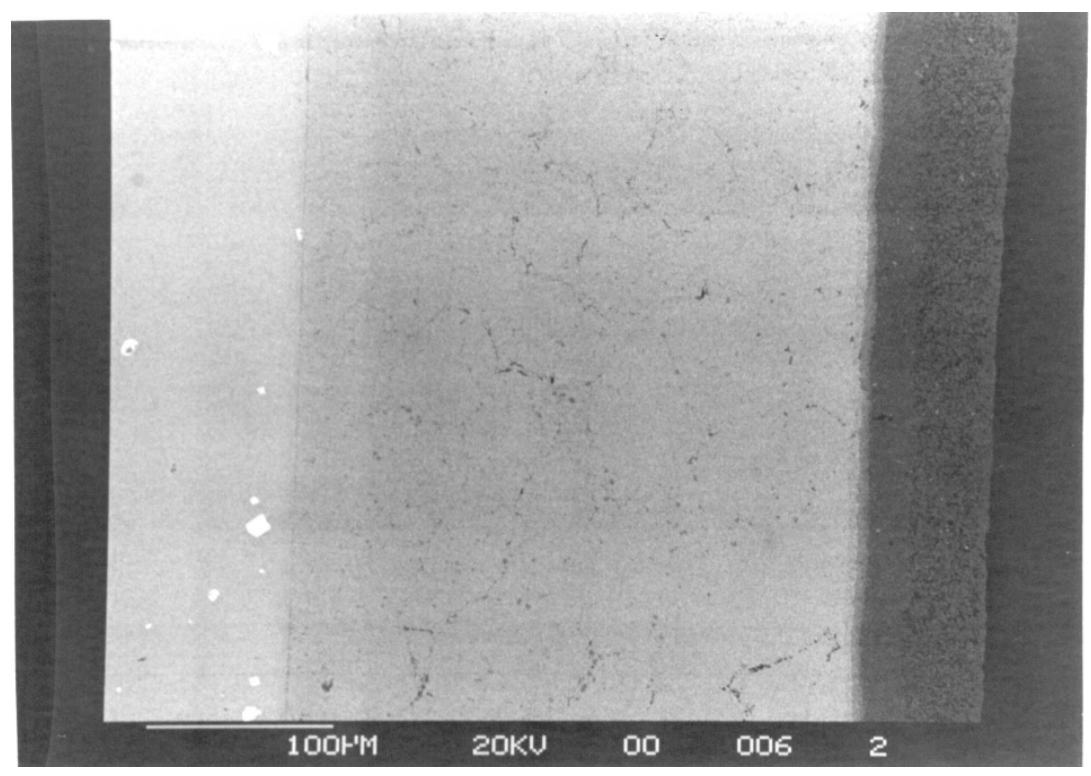

Figure $7 \quad$ Back scattered electron image of a graded overlay coating containing $\mathrm{Cr}_{3} \mathrm{C}_{2}$ scavenger phases 


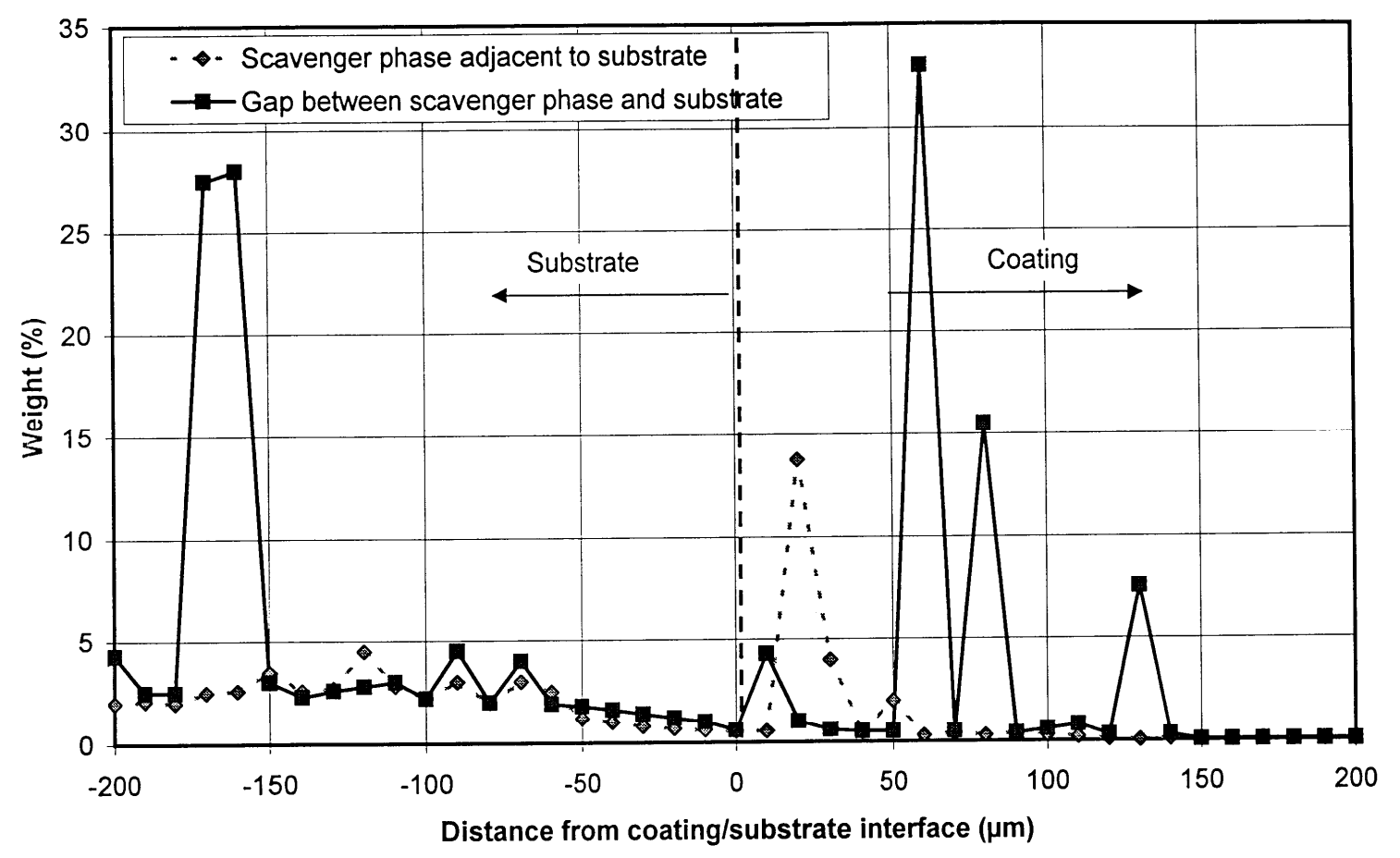

Figure 8 EDX profile for titanium, across the substrate coating interface after $500 \mathrm{~h}$ at $1080^{\circ} \mathrm{C}$ demonstrating the scavenger capability of $\mathrm{Cr}_{3} \mathrm{C}_{2}$ 


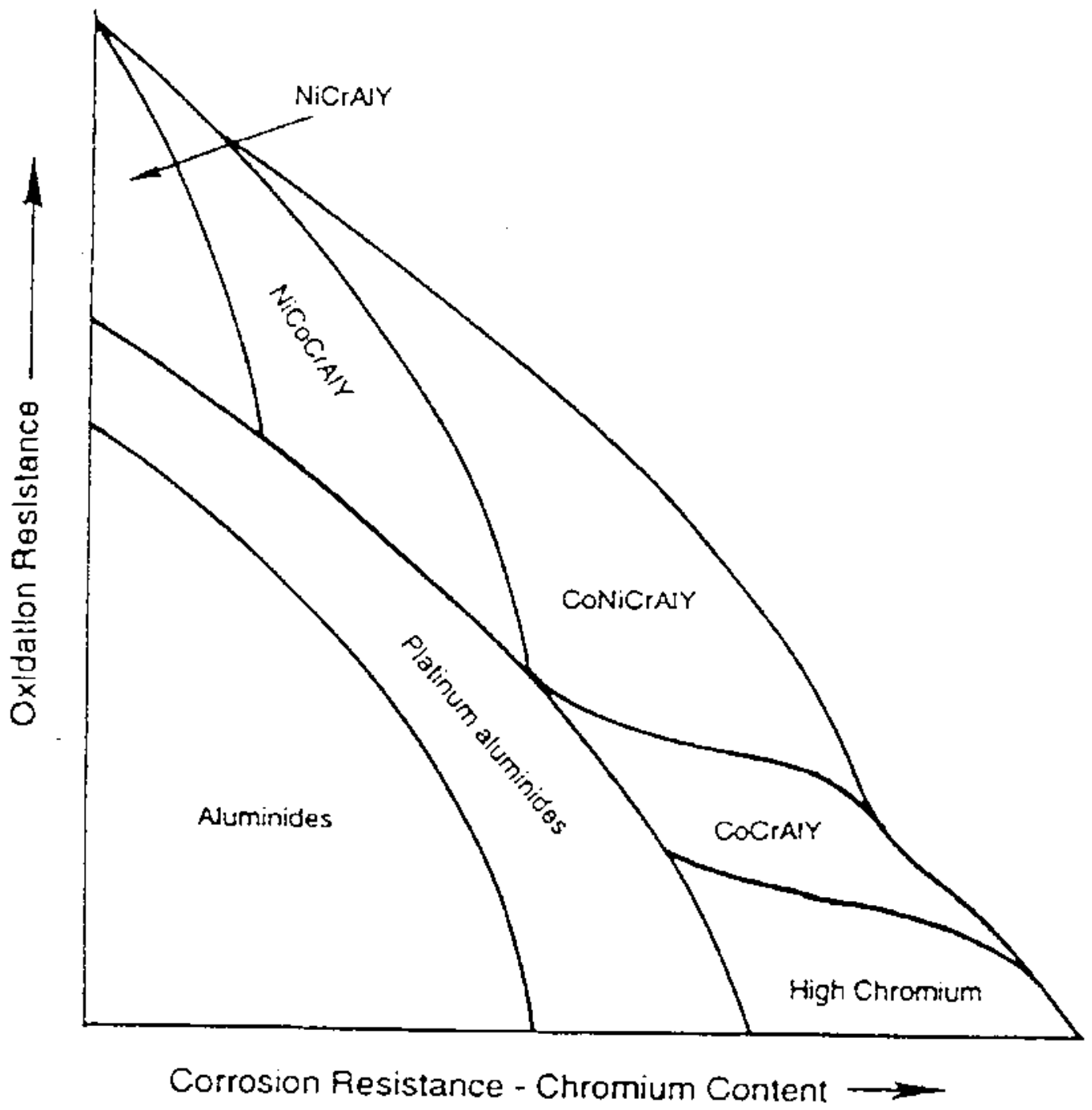

Fig. 1 


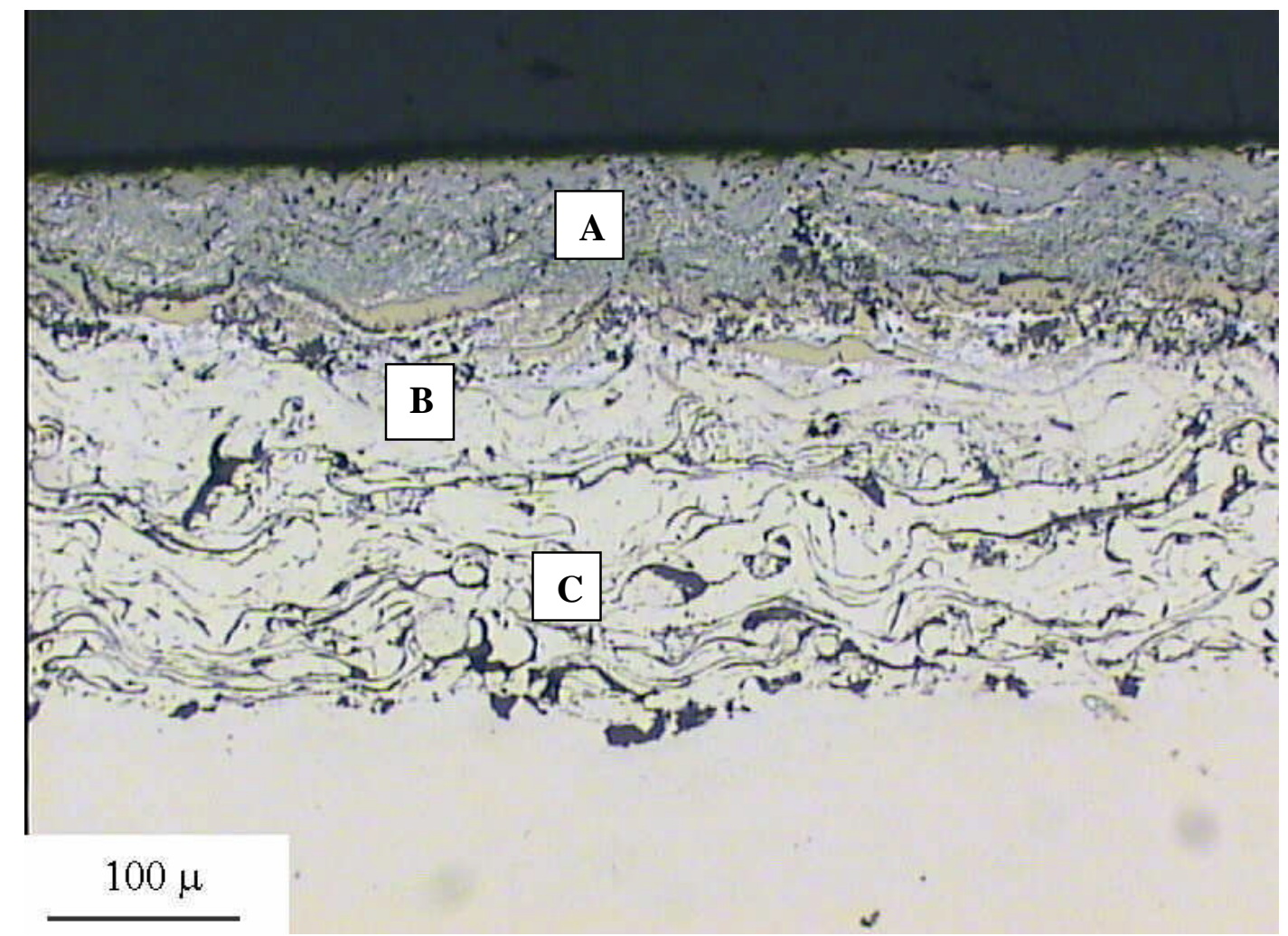

Fig. 4 
Fig 5 


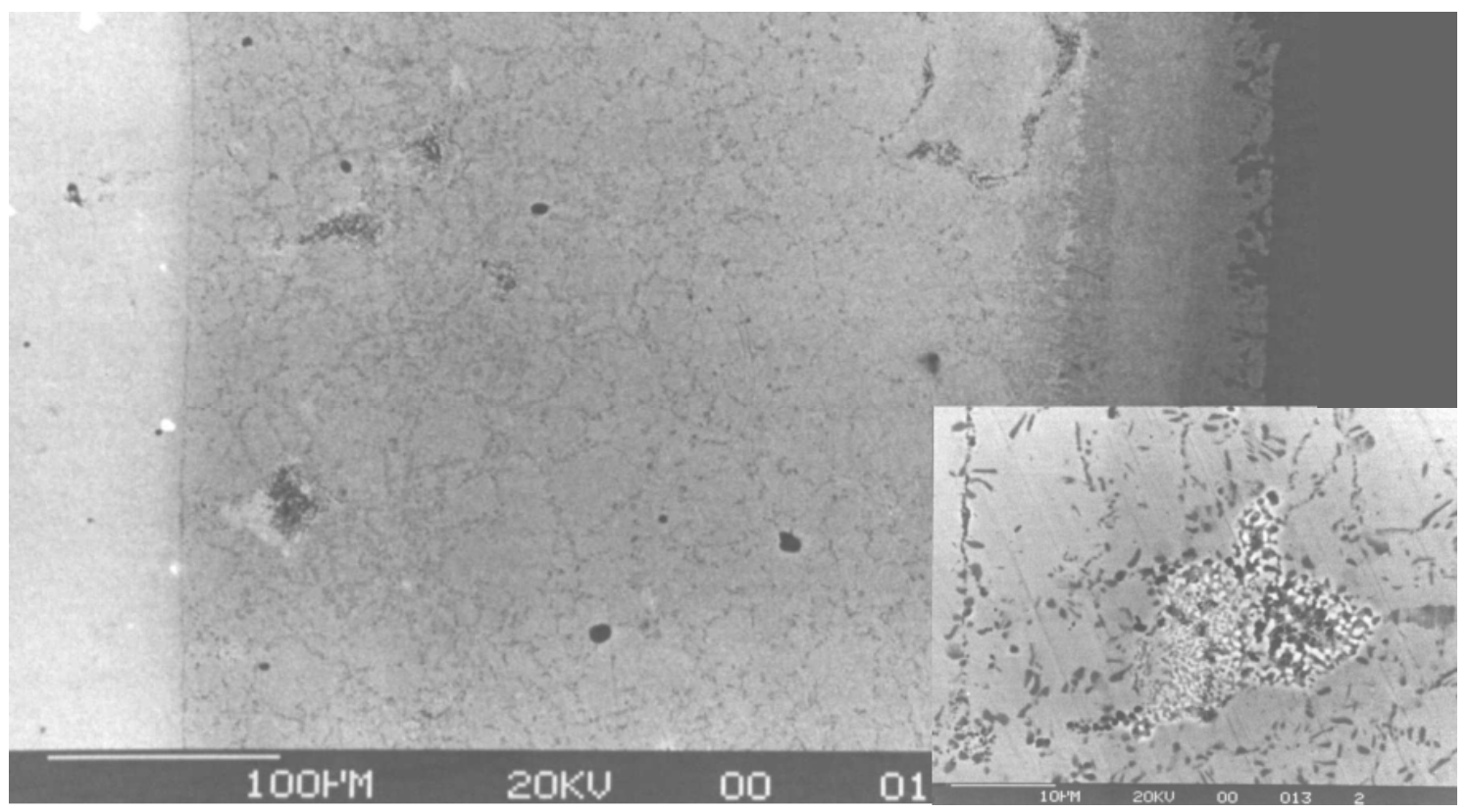

Figure 6 


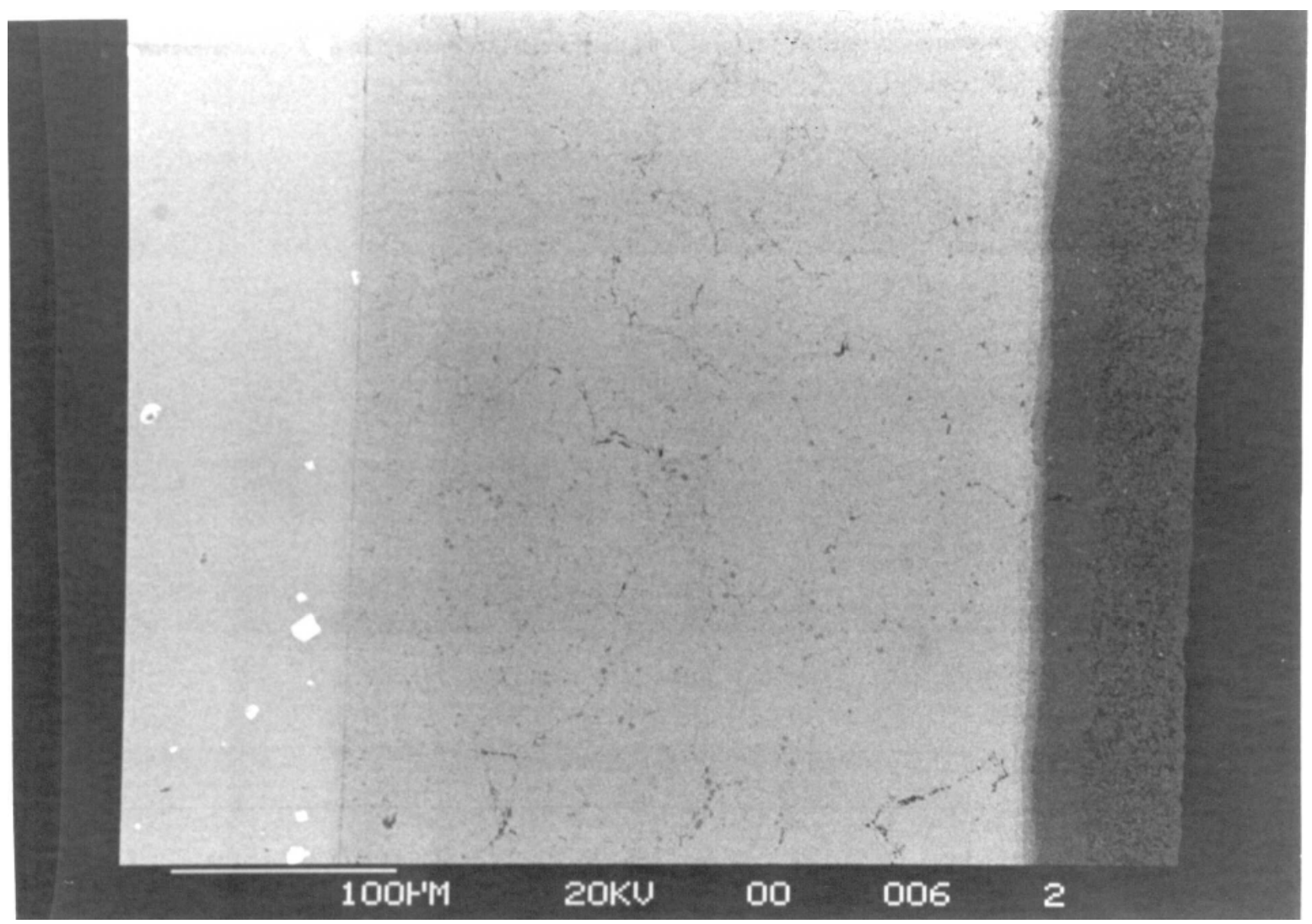

Fig. 7 


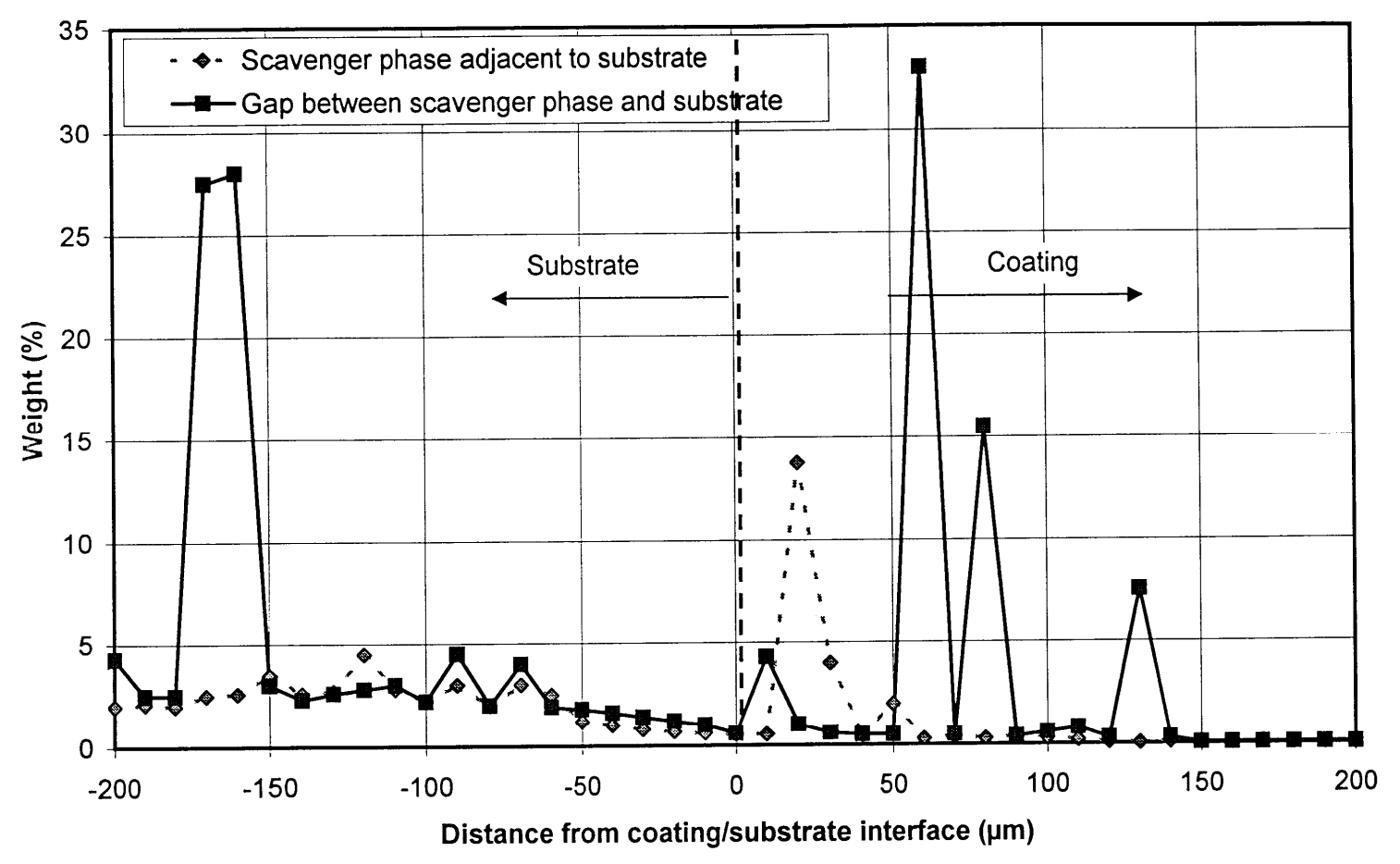

Fig. 8 
Table 1 Typical analysis of the three layered smartcoat structure, for a Coating based on Amdry 995 (SmC155)

\begin{tabular}{|l|l|l|}
\hline Position & Analysis (wt\%) & Comments \\
\hline A & Ni-15Cr-32Al to Ni-10Cr-21Al & Aluminium diffusion treatment \\
\hline B & Ni-60Cr-20Al to Ni-35Cr-40Al & Chromium rich corrosion barrier layer \\
\hline C & Co-32Ni-21Cr-8Al-0.5Y & Amdry 995 base composition \\
\hline
\end{tabular}

Table II Corrosion Performance of Smart Overlay Coatings at 700 and $800^{\circ} \mathrm{C}$ [32]

\begin{tabular}{|c|c|c|c|c|}
\hline $\begin{array}{l}\text { Coating } \\
\text { Reference }\end{array}$ & $\begin{array}{l}\text { Original } \\
\text { Coating } \\
\text { Thickness }(\mu \mathrm{m})\end{array}$ & $\begin{array}{l}\text { Coating Loss } \\
\text { @ } 700^{\circ} \mathrm{C}\end{array}$ & $\begin{array}{l}\text { Coating Loss } \\
\text { @ } 800^{\circ} \mathrm{C}\end{array}$ & Comment \\
\hline $\begin{array}{l}\text { RT22 } \\
\text { Sermetel } 1515\end{array}$ & $\begin{array}{l}82 \\
78\end{array}$ & $\begin{array}{l}41 \\
27\end{array}$ & $\begin{array}{l}(132)^{*} \\
5\end{array}$ & Reference coatings \\
\hline $\begin{array}{l}\text { SmC } 105 \\
\text { SmC } 105 \mathrm{H}\end{array}$ & $\begin{array}{l}275 \\
202\end{array}$ & $\begin{array}{l}97 \\
73\end{array}$ & $\begin{array}{l}44 \\
15\end{array}$ & $\begin{array}{l}\text { Over aluminised } \\
\text { MCrAlY Coatings }\end{array}$ \\
\hline $\begin{array}{l}\text { SmC } 153 \\
\text { SmC } 155 \\
\text { SmC } 155 \mathrm{H}\end{array}$ & $\begin{array}{l}446 \\
350 \\
280\end{array}$ & $\begin{array}{l}48 \\
26 \\
28\end{array}$ & $\begin{array}{l}19 \\
25 \\
56\end{array}$ & $\begin{array}{l}\text { SMARTCOAT } \\
\text { variants }\end{array}$ \\
\hline
\end{tabular}

(*) Corrosion penetration through the coating into the IN738 substrate. 


\section{$\underline{\text { List of Figures }}$}

Figure 1 Relative oxidation and corrosion resistance of high temperature coating Systems [21,22]

Figure 2 Smart overlay coating concepts [31,32]

Figure 3 Iso-corrosion map at $750^{\circ} \mathrm{C}$ for $\mathrm{NiCrAl-based} \mathrm{coatings} \mathrm{under} \mathrm{type} \mathrm{II} \mathrm{hot}$ corrosion conditions [43]

Figure 4 A micrograph of Smartcoat SmC155 showing the three layered Microstructure that is characteristic of Smartcoat.

Figure 5 Corrosion morphologies of SMARTCOAT SmC 155H, compared to RT22 (platinum aluminide) and an over aluminised CoNiCrAlY using a salt recoat test procedure $\left(80 \% \mathrm{Na}_{2} \mathrm{SO}_{4} / 20 \% \mathrm{~K}_{2} \mathrm{SO}_{4}\right.$ recoated at $0.3 \mathrm{mg} / \mathrm{cm}^{2}$ every $20 \mathrm{~h})$

Figure 6 Back scattered electron image of $\mathrm{Al}_{2} \mathrm{Y}$ dispersed phase in a HIPped Smart coating.

Figure $7 \quad$ Back scattered electron image of a graded overlay coating containing $\mathrm{Cr}_{3} \mathrm{C}_{2}$ scavenger phases

Figure 8 EDX profile for titanium, across the substrate coating interface after $500 \mathrm{~h}$ at $1080^{\circ} \mathrm{C}$ demonstrating the scavenger capability of $\mathrm{Cr}_{3} \mathrm{C}_{2}$ 


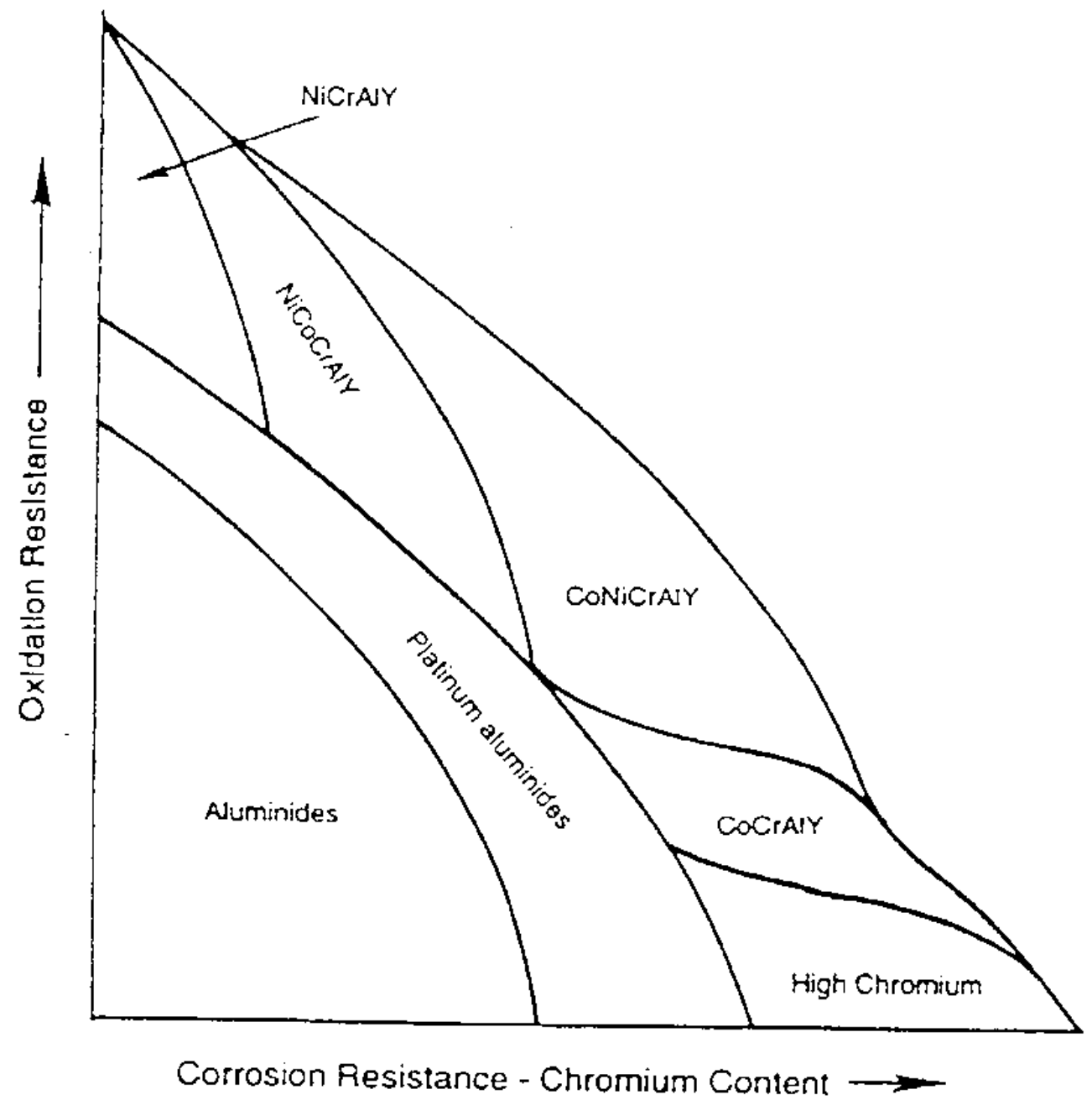

Fig. 1 


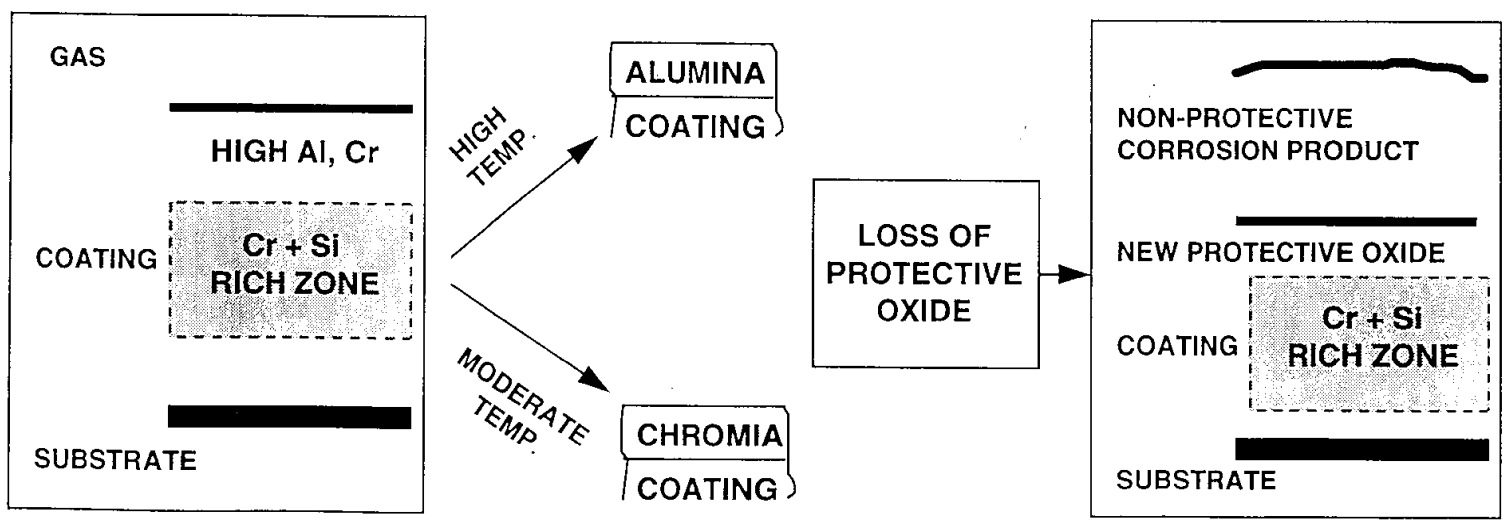

Fig. 2 


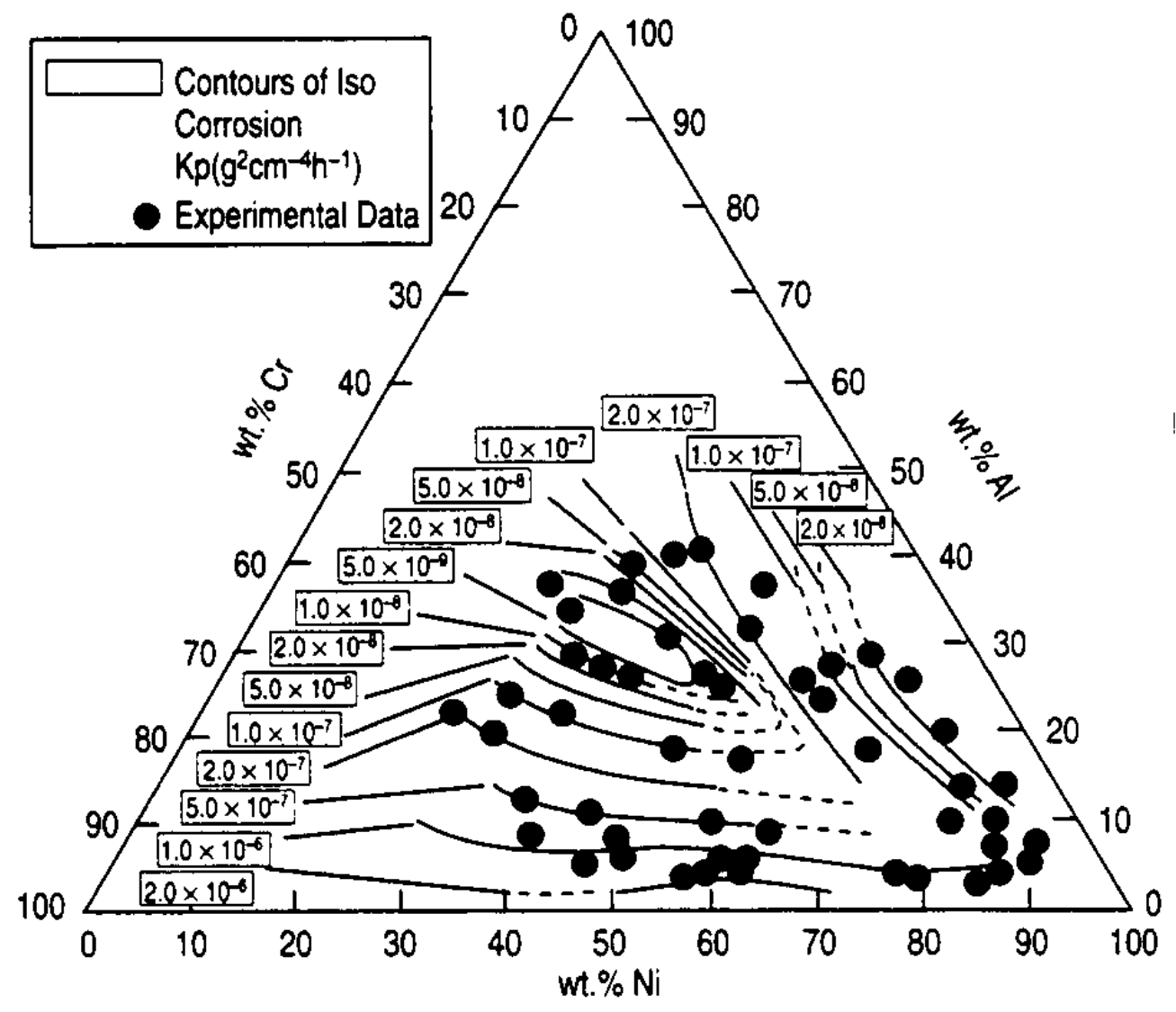

Fig. 3. 